\title{
PENINGKATAN BANGUNAN PENGAMAN PANTAI DESA KUNJIR LAMPUNG SELATAN PASCA TSUNAMI SELAT SUNDA 2018
}

\author{
HASSANAL ALI ${ }^{1}$, Dr. ANY NURHASSANAH, ST., M.T. ${ }^{2}$ \\ Program Studi Teknik Sipil, Fakultas Teknik, Universitas Bandar Lampung, \\ Jl. Zainal Abidin Pagar Alam No. 26 Labuhan Ratu Bandar Lampung, 0721-701979 \\ E-mail : alihassanal77@gmail.com, any_nurhasanah@ubl.ac.id
}

\begin{abstract}
The beach located in Kunjir village of South Lampung district is a coastal area in southern Lampung province longways $\pm 160 \mathrm{~km}$ facing to Lampung bay. At 22 December 2018 tsunami occurred because of undersea landslide caused by child of Krakatoa eruption in Sunda strait sea area. The tsunami elevation striking Kunjir beach was estimated to be 1.5 to 2.5 meter from ground level with inundation distance between $30 \mathrm{~m}$ to $50 \mathrm{~m}$ from the coastline, while the peak elevation of the revetment construction before tsunami striking was $\pm 3.5 \mathrm{~m}(\mathrm{MSL}=0)$. Therefore, coastal protection construction improvements by estimating empty stone revetment is required to provide protection against extreme sea wave or tsunami in the future.

The collected data included data of coastal damage, topography and bathymetry, anticipated wave elevation estimation, tsunami wave elevation, and revetment construction estimation. This research used ordinary wave estimation, tsunami wave and peak elevation to be estimated by using run-up and they were analyzed according to Bambang Triatmodjo formula.

In this research, the author evaluated the existing revetment construction in form of empty stone structures. The evaluation and estimation results produced revetment construction top elevation of $5.0 \mathrm{~m}$ and the construction height of $5.6 \mathrm{~m}$ for ordinary wave and revetment construction top elevation of $7.0 \mathrm{~m}$ and the construction height of $7.6 \mathrm{~m}$ for tsunami wave.
\end{abstract}

Keywords : :Tsunami, Revetment, Kunjir. 
PENDAHULUAN

Pantai Kunjir Kabupaten Lampung Selatan merupakan kawasan pantai di sebelah selatan Propinsi Lampung yang terletak di pesisir pantai Kabupaten Lampung Selatan yang memanjang $\pm 160 \mathrm{Km}$ berhadapan dengan Teluk Lampung. Pada musim tertentu sering terjadi hantaman gelombang pasang di beberapa tempat yang mengakibatkan erosi pantai dan rusaknya bangunan. Tanda kerusakan dapat dilihat dari rusaknya bangunan yang berada dipinggir pantai, baik sarana dan prasarana seperti jalan, jembatan, serta rumah penduduk, sekolah dan tempat ibadah.

Pada tanggal 22 Desember 2018 terjadi tsunami yang disebabkan oleh longsor bawah laut akibat letusan Anak Krakatau di perairan Selat Sunda. Tsunami yang terjadi menghantam beberapa kawasan di daerah pesisir Banten dan Lampung, Indonesia. Salah satu kawasan yang terdampak cukup parah akibat Tsunami Selat Sunda tersebut antara lain pantai-pantai di pesisir Kabupaten Lampung Selatan, Provinsi Lampung. Pertanggal 14 Januari 2019, diketahui korban jiwa di wilayah Kabupaten Lampung Selatan adalah 118 orang meninggal dunia, 11.810 orang luka-luka dan hampir 7000 orang mengungsi (BNPB).

Diketahui bahwa elevasi puncak dari masing-masing bangunan pengaman pantai tersebut berada di bawah ketinggian gelombang tsunami yang menghantam Pantai Kunjir
Kabupaten Lampung Selatan.

Ketinggian tsunami yang menghantam pantai kunjir diperkirakan mencapai 1,5 - 2,5 m dari ground level dengan jarak inundasi 30 - $50 \mathrm{~m}$ dari garis pantai, sedangkan elvasi puncak ketika bangunan revetment sebelum diterjang tsunami yang telah terbangun berkisaran + 3,5 $\mathrm{m}(\mathrm{MSL}=0)$, dengan kemiringan struktur bervariasi 1:1 dan 1:1,5 dan tinggi gelombang rencana $1,25 \mathrm{~m}$. Untuk itu diperlukan meninggikan bangunan pengaman pantai agar aman baik terhadap gelombang ekstrim ataupun tsunami yang mungkin terjadi di waktu mendatang.

\section{METODELOGI}

\section{Sumber Data}

Pada tanggal 22 Desember 2018 terjadi tsunami yang disebabkan oleh longsor bawah laut akibat letusan Anak Krakatau di perairan Selat Sunda. Tsunami yang terjadi menghantam beberapa kawasan di daerah pesisir Banten dan Lampung, Indonesia. Salah satu kawasan yang terdampak cukup parah akibat Tsunami Selat Sunda tersebut antara lain pantai-pantai di pesisir Kabupaten Lampung Selatan, Provinsi Lampung. Pantai Kunjir merupakan salah satu tempat yang terdampak tsunami. kondisi bangunan pengaman pantai yang ada di lokasi juga mengalami kerusakan ringan dan sedang.

Dalam penyelesaian ini penulis meyusun berdasarkan data kajian Penanganan Kerusakan Infrastruktur Pengaman Pantai Pasca Tsunami Selat 
Sunda di Kabupaten Lampung Selatan tahun 2019 oleh Pusat Penelitian dan Pengembangan Sumber Daya Air Badan Penelitian. Data yang digunakan merupakan data sekunder yaitu data untuk keperluan pendukung peningkatan bangunan pengaman pantai desa Kunjir Lampung Selatan berupa data, data gelombang.

\section{PenentuanWaktuPenelitian}

Pencatatan arus lalu lintas kendaraan dilakukanselama 12 jam. Darihasilpencatatanselanjutnyadikelom pokkanpola aruslalu-lintasharianyang terjadi. DataLHRtercatatyang diperoleh dipakai untukpenghitungan pendekatankeadaan rata-rata wilayah sesaat.Waktu penelitiandilakukan mulai dari Pukul 06.00-18.00 pada hari Senin dan pukul 09.00-21.00 pada hari Sabtu, pengambilandataLHRselama

2hari.Pengambilan

data kecepatanspacemean speed diambil pada saat jam puncak pagi, siang dan sore.

\section{Data Gelombang Tsunami}

Gelombang tsunami yang diperkirakan menerjang pantai Kunjir Kabupaten Lampung Selatan mencapai $1.5-2.5 \mathrm{~m}$ dari ground level dengan jarak inundasi sekitar $30-50 \mathrm{~m}$ dari garis pantai.

\section{Bangunan Revetment}

Fungsi utama bangunan revetment adalah sebagai pelindung pantai terhadap erosi dan limpasan gelombang (overtopping) ke darat. Data-data hasil pengukuran untuk perhitungan bangunan revetment diantaranya :
- Muka Air Tertinggi (HWL = $+0,51 \mathrm{~m}$

- $\quad$ Muka Air Tinggi Rerata (MSL) = $0,00 \mathrm{~m}$

- Kedalaman pada kaki struktur $($ LLWL $)=-0,68 \mathrm{~m}$

\section{ANALISIS DAN PEMBAHASAN}

\section{Gelombang Biasa}

Perhitungan gelombang biasa dengan menggunakan data dari detail desain pengaman pantai Kunjir Kabupatenn Lampung Selatan.

a. Kedalaman air di lokasi bangunan berdasarkan HWL dan LWL adalah : HWL $=+0,51-(-0,68)=1,19 \mathrm{~m}$ MSL $=0,00-(-0,68)=0,68 \mathrm{~m}$ LLWL $=-0,68-(-0,68)=0,00 \mathrm{~m}$

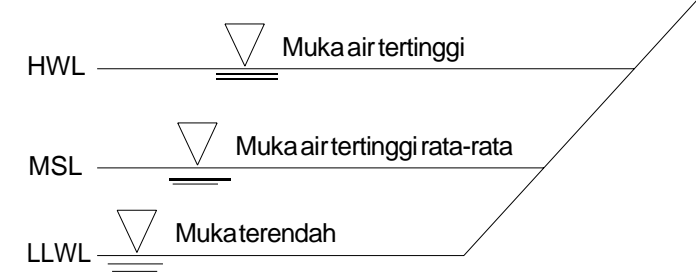

\section{Gelombang Tsunami}

b. Kedalaman air di lokasi bangunan berdasarkan HWL dan LWL adalah :

HWL $=+2,50-(-0,68)=3,18 \mathrm{~m}$ MSL $=0,00-(-0,68) \quad=0,68 \mathrm{~m}$ LLWL $=-0,68-(-0,68)=0,00 \mathrm{~m}$

Gelombang maksimum / Tinggi gelombang H33 = 2,5 m

Periode maksimum / Periode gelombang T33 = 6,48 detik 


\section{KESIMPULAN}

Dari hasil perhitungan bangunan revetment menggunaan batu kosong di lokasi Pantai Kunjir, didapatkan beberapa kesimpulan yaitu ;

a. Berdasarkan gelombang biasa yang di dapat geombang signifikan (Hs) didapat $\mathrm{H} 33=1,94 \mathrm{~m}, \mathrm{~T} 33=6,48$ detik

b. Dimensi bangunan revetment struktur batu kosong yaitu :

- Elevasi puncak bangunan revetment $=5,0 \mathrm{~m}$

- Tinggi bangunan $=5,6 \mathrm{~m}$

- Berat batu lapis lindung $=1,21$ ton

- Lebar puncak bangunan revetment $=3 \mathrm{~m}$

- Tebal lapis lindung $=2 \mathrm{~m}$

c. Berdasarkan gelombang tsunami biasa yang di dapat geombang signifikan $(\mathrm{Hs})$ didapat $\mathrm{H} 33=2,5$ $\mathrm{m}, \mathrm{T} 33=6,48$ detik

d. Dimensi bangunan revetment struktur batu kosong yaitu :

- Elevasi puncak bangunan revetment $=7,0 \mathrm{~m}$

- Tinggi bangunan $=7,6 \mathrm{~m}$

- Berat batu lapis lindung $=2,59$ ton

- Lebar puncak bangunan revetment $=3$

- Tebal lapis lindung $=2 \mathrm{~m}$

\section{Saran}

Sebelum Dari perhitungan yang telah dilakukan, saran yang diberikan anatara lain untuk Pusat Penelitian dan Pengembangan Sumber Daya Air Badan
Penelitian, perbaruhi atau update data gelombang minimal 10 tahun terakhir.

\section{DAFTAR PUSTAKA}

INAKKO Internasional Konsulindo, PT. (2010), Detail Desain Pengaman Pantai Kunjir Kunjir Kabupaten Lampung Selatan. Jakarta Selatan : PT. INAKKO.

Kumparan. Hal-hal penyebab tsunami. Diakses $20 \quad$ Juli 2020 https://kumparan.com/kumparansai ns/hal-hal-penyebab-tsunamigempa-bumi-erupsi-sampaimeteor-jatuh$\underline{1545535931623659442}$

Pusat Penelitian dan Pengembangan Sumber Daya Air Badan Penelitian. (2019), Kajian Penanganan Kerusakan Infrastruktur Pengaman Pantai Pasca Tsunami Selat Sunda di Kabupaten Lampung Selatan Tahun 2019.

Studio Belajar. Bagaimana proses terjadi tsunami. Diakses 20 Juli 2020 melalui https://www.studiobelajar.com/pros es-terjadinya-tsunami/ 
Supriyanti, Sari. (2016). Analisis Alternatif Bangunan Revetment Menggunakan Batu Kosong Di Pantai Desa Pugung Penengahan Kecamatan Lemong Kabupaten Pesisir Barat. Bandar Lampung

Triatmodjo, Bambang. (1999). Teknik Pantai. Yogyakarta : Beta Offset. 